\title{
Uncovered Interest Parity: Are Empirical Rejections of It Valid?
}

\author{
Jose Olmo \\ City University, London \\ Keith Pilbeam \\ City University, London
}

\begin{abstract}
There is a vast empirical literature rejecting uncovered interest parity(UIP) on the basis of regressions of the actual exchange rate change against the forward premium/discount. In this paper, whilst we confirm the conventional regression analyses, we argue that they constitute only an indirect test of UIP and that there are serious econometric flaws in such regressions that make them an unreliable means of testing for UIP. Instead, we propose a two new profitability based tests of the UIP condition based on actual dollar returns of being in the domestic and foreign currency and we find evidence that in fact the UIP condition in fact seems to be holding for three of the four parities studied even though the conventional test would have rejected UIP in all four cases. Not only do our economically more meaningful profitability based tests lead us to accept the UIP condition for three of four currencies studied but they also seem to offer superior econometric properties compared to the conventional regression analyses.
\end{abstract}

- JEL Classification : F30, F32, G15

- Key Words: efficient market hypothesis, forward discount puzzle, uncovered interest parity

\footnotetext{
*Corresponding address: Jose Olmo: City University, London, e-mail: j.olmo@city.ac.uk, Keith Pilbeam: corresponding author: Department of Economics, City University, Northampton Square, London EC1V 0HB, United Kingdom, e-mail: k.s.pilbeam@city.c.uk. 


\section{Introduction}

The UIP condition has been one of the most extensively studied efficiency conditions in economics. Despite its sound theoretical underpinnings, it has been conclusively rejected at the empirical level. In their paper Baillie and Bollerslev (2000 p.472) argue that: "The forward premium anomaly has become a well established regularity and is generally regarded as being one of the most important unresolved paradoxes in international finance." Excellent surveys documenting the rejection are contained in Hodrick (1987) and Engel (1996). The empirical rejection of the condition is of importance because the UIP condition is at the heart of the monetary models of exchange rate determination and it is extensively used in most open economy macroeconomic models. In rejecting the UIP condition a variety of different and competing hypotheses have been put forward to explain why it does not seem to hold, these include risk premia (possibly time varying), the peso problem and irrational foreign exchange market speculation. However, despite extensive research attempting to explain why UIP does not hold little progress has been made on identifying the culprit.

In this paper, we argue that the empirical rejection of UIP may in fact be an invalid statistical phenomenon. In particular, we note that conventional regression analyses of the actual change in the exchange rate against the forward premium/ discount are plagued by econometric problems that make the parameter estimates unreliable. More importantly, we argue that such regressions are only indirect tests of the UIP condition. An economically superior test of the UIP condition is used to examine whether excess profits can be made by switching one's capital between the domestic and foreign currency. We conduct two such tests, one involves comparing the dollar based returns of being in the foreign currency with the risk free dollar based return of remaining in the US dollar. The second compares dollar returns of keeping one's capital in the high interest rate currency as opposed to the low interest rate currency. Contrary to what the conventional regression analyses would have indicated, which is a rejection of the UIP condition, in three of the four cases we find evidence that UIP has in fact been holding. Our results suggest that solving one of the great puzzles of international finance is not quite as difficult as the existing literature suggests.

The paper is structured as follows: Section II looks at the conventional tests of the UIP condition. In Section III we introduce the idea of profitability tests and discuss a set of what we argue are more direct and economically meaningful tests 
of the UIP based on two different trading strategies that look for excess returns. We show that there is strong reason to accept the UIP condition for three of the four currencies studied. Only in the case of the dollar-pound parity we are able to confirm the conventional rejection of the UIP condition. Section IV concludes with some implications derived from our research. The figures are gathered in an appendix.

\section{Forward Rates, Covered Interest Parity and the UIP Condition}

It is well known that the forward exchange rate quoted in the foreign exchange market is based upon the covered interest parity arbitrage condition. For the purposes of this paper, rather than use the actual forward exchange rate we generated a set of forward exchange rates based upon this arbitrage condition. Whilst the forward rates we generated are extremely close to the actual forward exchange rate this procedure makes our results robust to any timing mismatches between the interest rates, spot exchange rates and forward exchange rates ${ }^{1}$ :

$$
F_{t}=\frac{\left(1+r_{t}\right)}{\left(1+r_{t}^{*}\right)}
$$

where $S_{t}$ is the spot exchange rate at time $t$ defined as dollars per unit of foreign currency, $F_{t}$ is the forward exchange rate at time $t, r_{t}$ the domestic interest rate and $r_{t}^{*}$ is the foreign interest rate. ${ }^{2}$

Taking logs of equation (1) means this condition is approximated by the following

$$
f_{t}-s_{t}=r_{t}-r_{t}^{*}
$$

where $f_{t}$ is the $\log$ of the forward exchange rate at time $t$ and $s_{t}$ is the log of the spot exchange rate at time $t$.

If one assumes that there is perfect capital mobility, no transaction cots or taxes

${ }^{1}$ We checked our results using actual forward rates but the results are almost identical to those generated by our use of the CIP condition.

${ }^{2}$ Note the above equation needs modify according to whether one is looking at the one, three, six month or 12 month time horizon using the appropriate interest rate for the time horizon under consideration. All the relevant adjustments have been made for the purposes of this paper. 
and that investors are risk neutral (or alternatively that there is no risk premium) then the Uncovered Interest Parity condition can be expected to hold. According to UIP the high interest rate currency is expected to depreciate at a rate equal to the interest rate differential between the high and low interest rate currency so that the expected returns are equalized. The UIP condition is given by equation (2):

$$
E s_{t+1 / t}-s_{t}=r_{t}-r_{t}^{*}
$$

where $E s_{t+1 / t}$ is the log of the expected exchange rate for time $t+1$ at time $t$, and $E s_{t+1 / t}-s_{t}$ is the expected rate of depreciation of the currency.

If we assume that rational expectations prevail in the foreign exchange market and that there is no risk premium then on average the actual log of the exchange rate at time $t+1$ that is $s_{t+1}$ will be equal to the $\log$ of the forward rate $f_{t}$ and a random error, that is:

$$
s_{t+1}=f_{t}+u_{t+1}
$$

where $u_{t+1}$ is a random error term following a normal distribution and a mean of zero.

Also the log of the expected exchange rate will be equal to the log of the forward exchange rate, that is:

$$
E s_{t+1 / t}=f_{t}
$$

Combining equations (2) to (5) and rearranging yields a testable form of UIP given by equation (6):

$$
\left(s_{t+1}-s_{t}\right)=\left(f_{t}-s_{t}\right)+u_{t+1}
$$

For regression purposes this means that UIP can be tested by equation (7):

$$
\left(s_{t+1}-s_{t}\right)=\alpha+\beta\left(f_{t}-s_{t}\right)+u_{t+1}
$$

In Table 1 we report regression estimates of equation 1 for four major currencies against the US dollar namely the swiss-franc, yen, deutsch mark/euro and pound sterling. The dataset consists of three month forward and spot exchange rates 
Table 1. Estimates Equation $\left(s_{t+1}-s_{t}\right)=\alpha+\beta\left(f_{t}-s_{t}\right)+u_{t+1}$

\begin{tabular}{ccccccc}
\hline Currency pair & $\alpha$ & $\beta$ & R2 & JB & SC-LM & ARCH \\
\hline dollar/swiss franc & -0.01 & -1.13 & 0.019 & 2.66 & 1.49 & 1.23 \\
& $(0.05)$ & $(0.12)$ & & $(0.26)$ & $(0.21)$ & $(0.30)$ \\
dollar/yen & -0.02 & -1.93 & 0.048 & 13.3 & 2.13 & 0.88 \\
& $(0.007)$ & $(0.01)$ & & $(0.001)$ & $(0.10)$ & $(0.45)$ \\
dollar/euro & -0.006 & -0.55 & 0.004 & 0.44 & 2.26 & 0.38 \\
& $(0.31)$ & $(0.47)$ & & $(0.80)$ & $(0.08)$ & $(0.76)$ \\
dollar/pound & 0.009 & -1.42 & 0.03 & 5.16 & 3.40 & 0.25 \\
& $(0.11)$ & $(0.05)$ & & $(0.07)$ & $(0.02)$ & $(0.85)$ \\
\hline
\end{tabular}

Notes: p-values are in parentheses. JB is the Jarque-Bera test for normality of the residuals, SC-LM is the Breusch-Godfrey lagrange multiplier F-statistic for serial correlation -the alternative hypothesis has three lags and ARCH is the Arch F-statistic for conditional heteroscedasticity - the alternative hypothesis has three lags.

covering the period March, 1974 until March 2005 for these economies. ${ }^{3}$

The results we report in Table 1 are entirely consistent with those reported in the literature such as Fama (1984) and Maynard and Phillips (2001) in showing that uncovered interest rate parity is rejected for all of these markets. Most importantly, the slope in the regression in the regression is negative rather than the expected value of unity and significantly so in the case of the dollar-yen and dollar-pound parities. The results are fairly decisive rejections of UIP and they suggest that high interest rate currencies that would be expected to depreciate according to UIP have actually appreciated! In general, the residuals are well behaved, although closer examination shows that in the case of the dollar-yen parity they are not normally distributed and in the case of the dollar-pound parity there seems to be some evidence of autocorrelation.

There are three key reasons for the empirical failure of UIP that have been cited in the literature. One possible explanation is that it may be due to a risk premium (possibly time varying) but this idea is rejected by Frankel and Froot (1989). Another possible explanation is that it is due to inefficient speculation in the foreign exchange market causing either rational or irrational bubbles, see for,

${ }^{3}$ Eurodollar, eurosterling, euroyen euroswiss franc and eurodeutschmark/euroeuro rates and spot exchange rates were from globalfindata.com. Forward rates were generated from these data using the covered interest parity condition and were found to be extremely close to the set of actual forward rates from the same data source. 
example Cavaglia et al (1994) who detect both a risk premia and irrational expectations as explanations of the UIP puzzle and Mark and Wu (1998) who detect some evidence that noise traders may play a role. More recently, Baillie and Bollerslev (2000) have suggested that the empirical rejection of UIP may in fact be a statistical problem and despite a variety of attempts to improve the econometric properties of estimates of the UIP for example, Hansen and Hodrick (1980), Fama (1984), Taylor (1989) and Wang and Jones (2002) there has been very little progress in overturning the results of the conventional regression analyses. Recently Sarno et al (2006) shown that there are significant non linearities in deviations from UIP that help explain the poor results from estimations based upon linear regressions.

There is common agreement that the logarithmic spot price and forward rates are integrated of order one, $I(1)$. Also, Baillie and Bollerslev (2000) note that while daily exchange rate returns exhibit a pronounced volatility clustering the time series corresponding to the forward premium hardly shows departures from its expected value. Their results suggest that the failure of UIP may be a statistical phenomenon that occurs because of the very persistent autocorrelation in the forward premium implying that the standard unbiasedness of the regression may not hold, in other words, the order of integration of the dependent and explanatory variables are not the same. Following similar arguments to those introduced in Baillie and Bollerslev we argue for reasons that will be evident later on in this study that the failure of UIP is in fact a statistical phenomenon related to the difference of uncertainty levels underlying each side of the regression equation. There is ample evidence as shown in Figure 1 that the log-returns of spot prices are significantly more volatile than the forward premium.

The plots of the residuals in Figure 1 (see appendix) show clear evidence that the difference in volatilities in both sides of the conventional regression equation is one of the causes for the large amount of uncertainty found in the usual estimates of the slope parameter when testing UIP. The results make sense given the forward discount/premium is determined by the nominal interest rate differential between the currencies and therefore is the same regardless the variance exhibited by $s_{t}$. The standard regression equation is only likely to provide reliable results when the variance of $\Delta s_{t+1}$ is very low. 


\section{Profitability Based Tests of the UIP Condition}

The Uncovered Interest Parity relationship can be regarded as a market efficiency condition. In his classic study of market efficiency, Fama (1970 p.383) made the important point that an efficient market is one in which prices always "fully reflect" available information so that all unusual ex ante profit opportunities are eliminated. In the specific application to the foreign exchange market this implies that market participants use all relevant information bearing on the appropriate value of the exchange rate to produce a set of exchange rates (spot and forward) that does not provide an opportunity to make excess profits. It is somewhat surprising, and in fact a huge gap in the literature, that there have been no profitability based tests of the UIP condition and to illustrate the potential importance of this omission we find that Figure 2 is very informative in this regard. This chart depicts the cumulative total dollars of leaving 100 dollars of capital in US dollars to earn the US interest rate or alternatively the cumulative dollar total value of leaving the capital in the foreign currency to earn the foreign interest rate plus any appreciation (less any depreciation) of the foreign currency based on using the same interest rates used to generate our forward exchange rates and the rejection of UIP reported in Table 1. What is most interesting is that the dollar based cumulative return from keeping ones money in US dollars or in the foreign currency seem to be remarkably similar as one would expect if UIP were to hold for three of the four parities! It is certainly not what one would expect from the results reported in Table 1 using the conventional regression analysis. In fact, based on annualised returns as Table 2 shows it seems that it made very little difference as to whether the investor held their money in US dollars or the foreign currency to earn the foreign interest rate plus the appreciation/depreciation of the foreign currency. It makes next to no difference whether one holds one's money in US dollars or the foreign currency as one would expect when UIP holds.

Our simple graphical analysis and summary Table 2 seem to indicate there is something seriously wrong with the conventional regression results which reject UIP and we confirm this more rigorously by resort to two new simple profitability

Table 2. Annualized Dollar Returns of Holding Capital in US Dollars or Foreign Currency for the Period 1974Q1 to 2005Q1

\begin{tabular}{ccccc}
\hline US Dollar & Swiss Franc & Yen & Euro/DM & Pound \\
\hline $7.40 \%$ & $7.23 \%$ & $7.76 \%$ & $7.5 \%$ & $8.97 \%$ \\
\hline
\end{tabular}


based tests of the UIP condition.

In the first test we look at two possibilities facing the international investor; on the one hand leave all ones capital $X$ to grow at the rate $\left(1+r_{u s}\right)$ or secondly switch ones capital for three months and earn the foreign interest plus any appreciation or depreciation of the foreign currency. If the UIP condition holds then the expected excess return on being in the foreign currency should be zero. The test we conduct is expressed by equation (8) and the results are reported in Table 3:

$$
E\left[R_{t+1}^{*}\right]-E\left[R_{t+1}\right]=0
$$

where $E\left[R_{t+1}^{*}\right]$ is the return in dollar units of holding capital in the foreign currency and $E\left[R_{t+1}\right]$ is the return on holding capital at the US interest rate.

The expected excess return equation (8) can be rewritten as:

$$
E\left[R_{t+1}^{*}\right]-r_{t}=0
$$

To make a testable version of the UIP condition, we propose the following simple econometric test:

$$
R_{t+1}^{*}-R_{t+1}=\alpha+\varepsilon_{t+1}
$$

with $R_{t+1}^{*}$ the dollar return of holding capital in the foreign currency at the foreign

Table 3. Estimated Equation $R_{t+1}^{*}-R_{t+1}=\alpha+\varepsilon_{t+1}$

\begin{tabular}{cccccc}
\hline Currency pair & $\alpha$ & $\mathrm{R}^{2}$ & JB & SC-LM & ARCH \\
\hline \multirow{2}{*}{ dollar/swiss franc } & 0.001 & 0 & 3.28 & 1.53 & 0.67 \\
& $(0.76)$ & & $(0.19)$ & $(0.21)$ & $(0.57)$ \\
dollar/yen & 0.002 & 0 & 6.97 & 2.37 & 1.04 \\
& $(0.65)$ & & $(0.03)$ & $(0.07)$ & $(0.37)$ \\
dollar/euro & 0.002 & 0 & 1.44 & 2.67 & 0.39 \\
& $(0.70)$ & & $(0.48)$ & $(0.05)$ & $(0.65)$ \\
dollar/pound & 0.005 & 0 & 0.52 & 4.23 & 0.87 \\
& $(0.30)$ & & $(0.77)$ & $(0.006)$ & $(0.46)$ \\
\hline
\end{tabular}

Note $p$ values are in parentheses. 
rate of interest plus (less) any appreciation (depreciation) of the foreign currency, ${ }^{4}$ and $R_{t+1}$ the dollar return on holding capital at the US interest rate. UIP will hold if $\alpha=0$ and the error term is white noise. Note the regression is balanced if $R_{t+1}^{*}-R_{t+1}$ and the error term are stationary. If this is so, the OLS estimator provides consistent and efficient estimates of the parameters. If $\alpha \neq 0$ then this corresponds to a failure for UIP to hold.

Our empirical test based on excess returns reported in Table 3 provides very supportive results for UIP contrary to the conventional regression results. In all four cases we do not find evidence to reject the UIP condition in that the excess returns are not significantly different from zero. Furthermore, in general the residuals validate our regression analysis. The only exceptions are in the case of the dollar-yen parity where the Jarque-Bera statistic rejects normality and in the case of the dollar-pound parity where there seems to be some autocorrelation in the residuals.

As Figure 3 shows the residuals are well behaved and standard tests for the white noise hypothesis on $\varepsilon_{t}$ are not rejected. The inspection of the autocorrelation and partial autocorrelation for the residuals and for the square residuals do not uncover any serial dependence. The Breusch-Godfrey LM test and ARCH tests for the presence of serial dependence and heteroscedasticity are not significant either. In sum, the statistics depict the case of a Gaussian white noise.

Equation (10) is a novel and economically meaningful test of UIP, however it is not the only possible profitability test. If we were to take the conventional regression results with their negative $\hat{\beta}$, they suggest a simple strategy to make excess money, that is, for an investor to invest their capital in the high interest rate currency and to avoid investment in the low interest rate currency. This is because the negative beta estimates from conventional regression analyses imply that by being in the high interest rate currency an investor will also benefit from an appreciation whilst being in the low interest rate results in an underperformance since on average one also suffers from a depreciation of the currency and a clear violation of what one would expect if UIP was holding. Our high interest-low interest profitability test consists on comparing the dollar returns of investing one's capital in the market with highest nominal interest rate to the dollar returns from

\footnotetext{
${ }^{4}$ The dollar based return on the investment of dollars in the foreign currency is defined by:

$$
R^{*}{ }_{t+1}=\frac{S_{t}}{S_{t+1}}\left(1+r_{t}^{*}\right)-1
$$
}


investing ones capital in the currency with the lowest nominal interest rate. If UIP holds there should be no excess returns from a strategy which involves switching one's capital between the high and low interest rate currency over the lifetime of the investment. The relevant efficiency condition in this case is given by equation (11):

$$
E\left[R H_{t+1}\right]-E\left[R L_{t+1}\right]=0
$$

where $E\left[R H_{t+1}\right]$ is the expected dollar return from being in the high interest rate currency and $E\left[R L_{t+1}\right]$ is the expected dollar return from being in the low interest rate currency.

The economic interpretation of this condition in this context is that an investor does not obtain excess profits by placing their capital in either the high or low interest rate currency. The econometric test of the high interest rate-low interest rate test of UIP is given by equation (12):

$$
R H_{t+1}-R L_{t+1}=\alpha+\varepsilon_{t+1}
$$

The UIP will hold if $\alpha=0$ and the error term is white noise. Table 4 reports the outputs of the estimates in the testing regression equation give by equation (12):

As Table 4 shows the UIP condition holds for three of the four parities for which the conventional regression analysis would have said that it was not holding.

Table 4. Estimated Equation $R H_{t+1}-R L_{t+1}=\alpha+\varepsilon_{t+1}$

\begin{tabular}{cccccc}
\hline Currency pair & $\alpha$ & $\mathrm{R}^{2}$ & JB & SC-LM & ARCH \\
\hline \multirow{2}{*}{ dollar/swiss franc } & 0.002 & 0 & 7.91 & 1.14 & 0.76 \\
& $(0.65)$ & & $(0.02)$ & $(0.33)$ & $(0.51)$ \\
dollar/yen & 0.005 & 0 & 16.9 & 1.57 & 0.88 \\
& $(0.35)$ & & $(0.0)$ & $(0.19)$ & $(0.45)$ \\
dollar/euro & 0.009 & 0 & & & \\
& $(0.10)$ & & $(0.34)$ & $(0.21)$ & $(0.79)$ \\
dollar/pound & 0.01 & 0 & 1.06 & 1.96 & 0.87 \\
& $(0.005)$ & & $(0.58)$ & $(0.12)$ & $(0.47)$ \\
\hline
\end{tabular}

Note $p$-values are in parentheses. 
However, based upon this test, there is a fairly decisive rejection in the case of the dollar-pound parity. Tests of the residuals show that they behave as a white noise in all cases and are even Gaussian for the dollar-euro and dollar pound parities (that is, normally distributed as well as being white noise). We are not unduly disappointed by the rejection of UIP for the dollar-pound parity, the reason being that conventional regression analysis using the same dataset incorrectly rejects the UIP condition in all four cases. Our test clearly helps to distinguish between cases when UIP can be said to have held and the one parity that it did not appear to have held for. As such, we believe that our profitability based test represents a significant advance compared to the existing tests.

\section{Conclusions}

There has been a large amount of research that has rejected UIP based upon econometric tests of exchange rate changes against the forward discount/premium. In this paper we argue that due to differences between the volatility of the actual exchange rate change and the forward discount such rejections are unreliable and there is good reason to think that such analyses are plagued by econometric problems. More importantly, we argue that conventional regression analyses only constitute an indirect statistical test of the UIP condition. A more direct and relevant economic test of the UIP condition requires that there should be no systematic excess returns from different strategies that involve switching between the domestic and foreign currency. We have proposed two new profitability based tests of the UIP condition and our results are somewhat startling in that whereas the traditional regression based results would have decisively rejected UIP we find that there is strong reason to accept the UIP condition for three of the four currencies studied. Only in the case of the dollar-pound parity were we able to confirm the conventional rejection of the UIP condition.

The key advantage of our proposed profitability based tests is that they constitute a more direct test of the UIP condition and accord with the idea of an efficient market being one in which is difficult for market participants to make excess returns from pursuing rather simplistic trading strategies. Our tests based upon excess returns not only undermine the idea that UIP does not hold as a short run phenomena but also seem to possess superior econometric properties than can be obtained by using the conventional regression approach. The results of this paper suggest that foreign exchange markets are by and large efficient and that a 
substantial body of economic literature that has rejected the UIP condition due to either the market irrationality or the existence of time varying risk-premia or a combination of the two may need to be re-examined.

Finally, this paper has analyzed quarterly data on different exchange rates markets. Arguably, the low frequency of this data can affect our empirical results on tests of UIP pointing towards acceptance of the hypothesis when the effects of unexpected shocks hitting the economy can be smoothed out by aggregation of data. We believe it would be very interesting to replicate this analysis with data from higher frequencies, for example monthly data, given the availability of the type of data studied. Also, it would be very interesting to explore other alternative profitability tests given the ease of the techniques required to implement them. All these issues are ongoing research by the authors.

\section{Acknowledgements}

We are extremely grateful to participants at the European Economics and Finance Society annual conference of 2007 held at Sofia for many useful comments and two anonymous referees for very useful suggestions.

Received 25 October 2007, Revised 30 June 2008, Accepted 16 October 2008 


\section{Appendix}

Figure A1. Volatilities of the Exchange Rate Versus the Forward Premium/Discount Plots of $\Delta \mathrm{s}_{\mathrm{t}}+1$ ( $(-)$ ) and $\mathrm{ft}-\mathrm{s}_{\mathrm{t}}$ (-------) for different exchange markets for quarterly data (1974Q1 to 2005Q1).
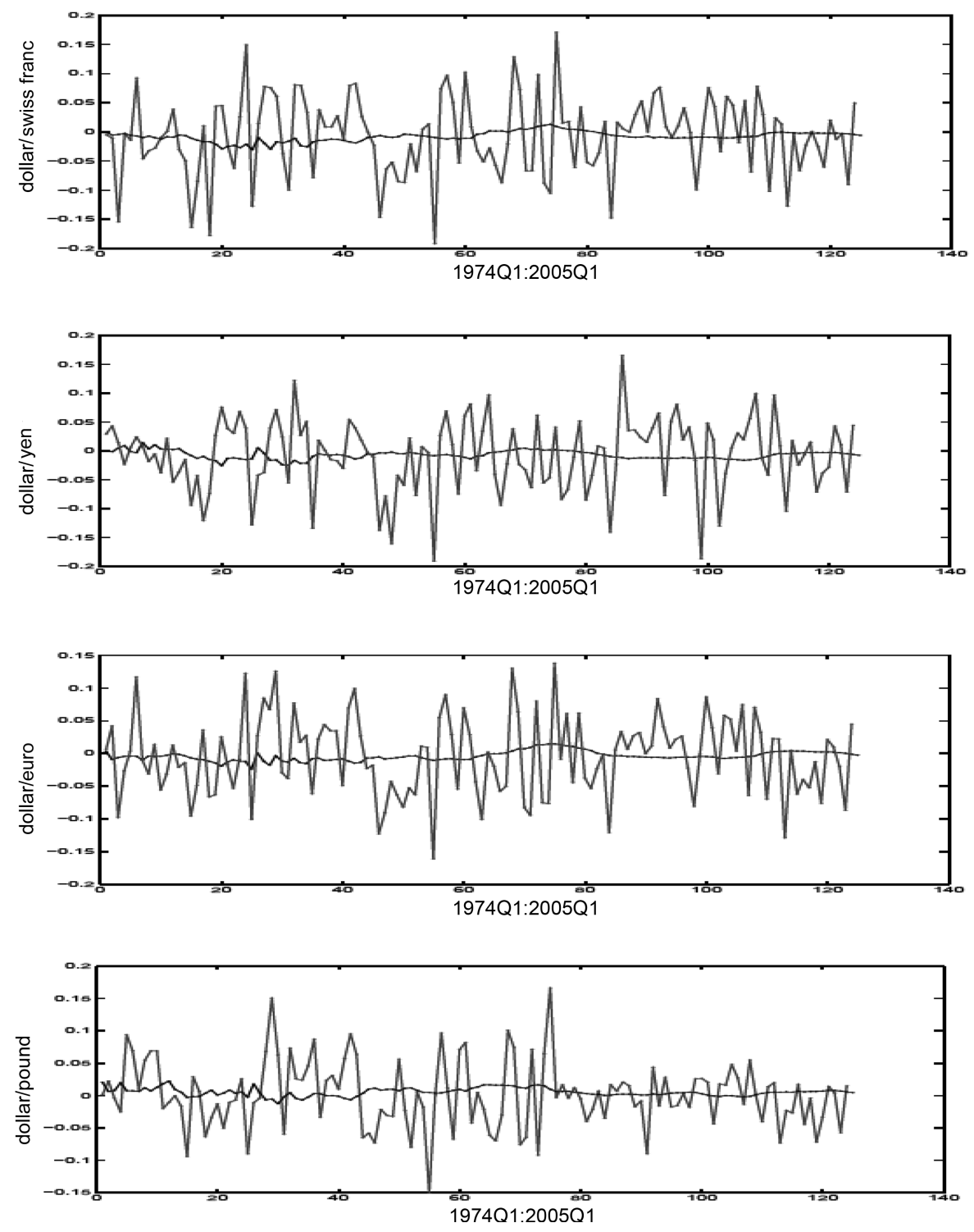
Figure A2. The Cumulative Dollar Sum of Keeping Capital in US Dollars or the Foreign Currency.

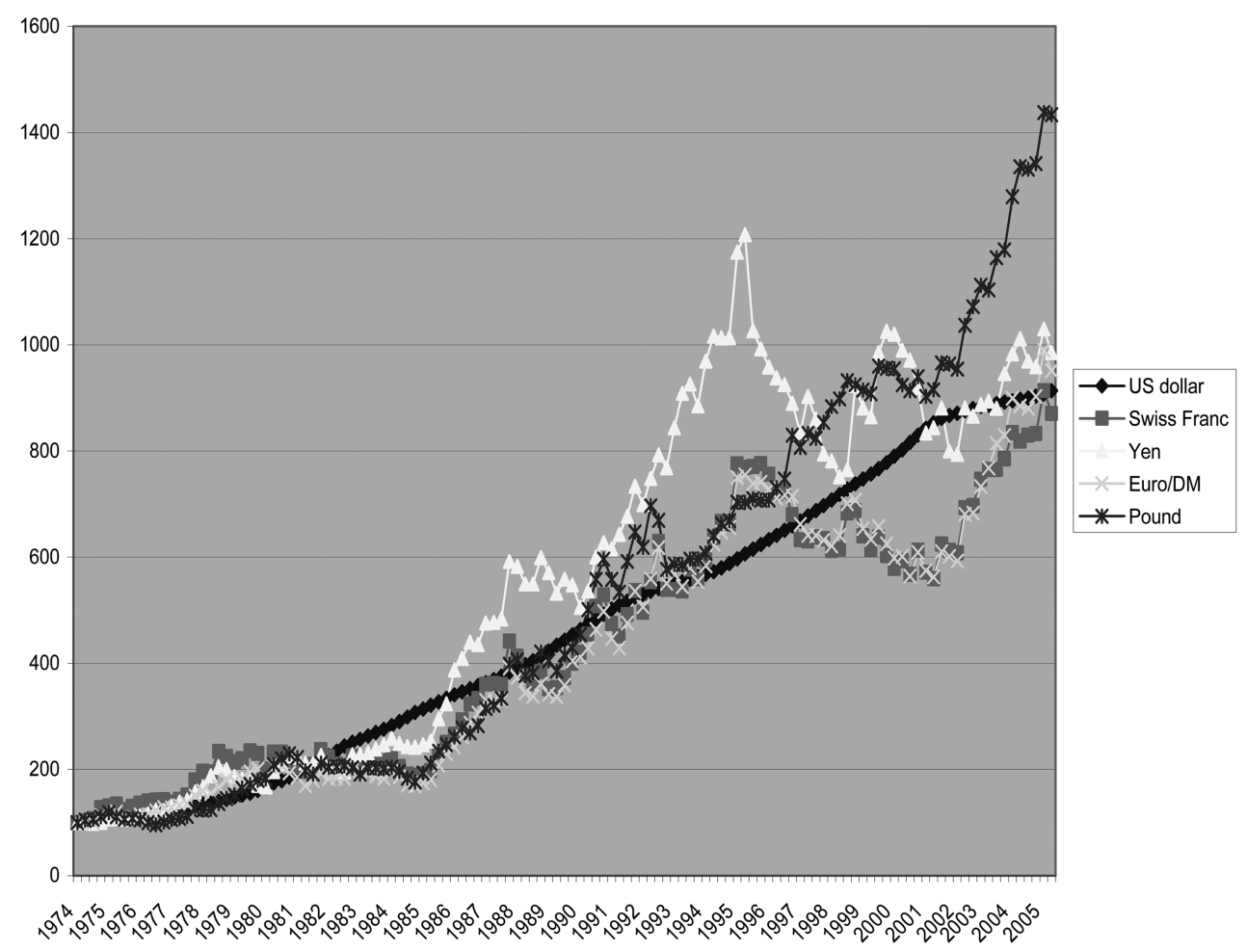


Figure A3. Residuals of Foreign Versus Domestic Dollar Based Returns Using Quarterly Data (1974Q1 to 2005Q1)
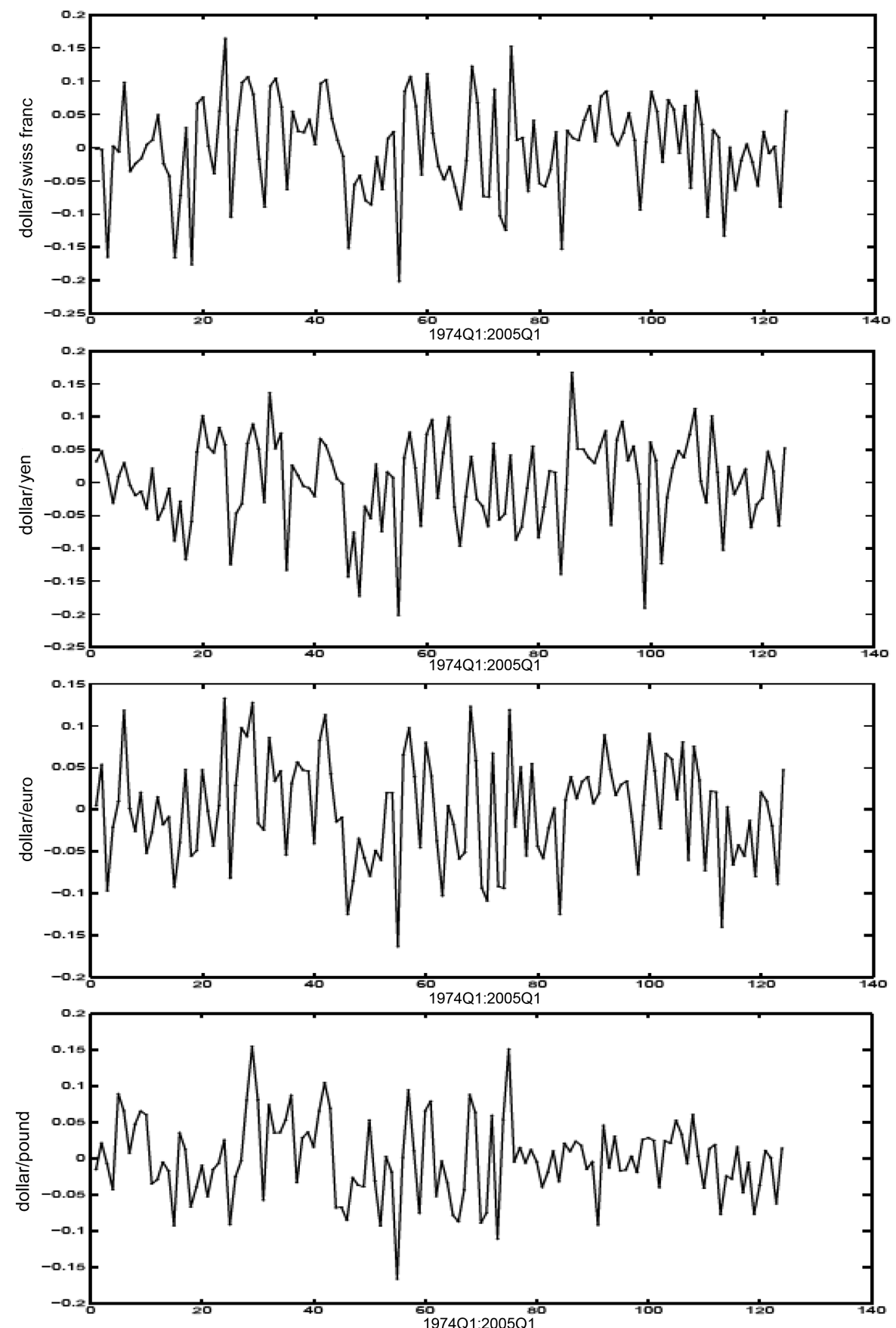


\section{References}

Baillie R.T. and Bollerslev T. (2000), "The Forward Premium Anomaly Is Not as Bad as You Think", Journal of International Money and Finance, Vol 19, pp.471-88.

Boothe P. and Longworth D. (1986), "Foreign Exchange Market Efficiency Tests: Implications of Recent Empirical Findings", Journal of International Money and Finance, Vol 5, pp.135-52.

Cavaglia, S. Vershoor W. and Wolff C. (1994), "On the Unbiasedness of Foreign Exchanges: Irrationality or a Risk Premium ?" Journal of Business, Vol 67, No 3, pp. 321-43.

Engel C. (1996), "The Forward Discount Anomaly and the Risk Premium: A Survey of Recent Evidence", Jounral of Empirical Finance, Vol 3, pp. 123-92.

Fama E. (1970), "Efficient Capital Markets: A Review of Theory and Empirical Work", Journal of Finance, pp. 383-417.

Fama E. (1984), "Forward and spot Exchange Rates", Journal of Monetary Economics, Vol. 19, pp. 319-338.

Frankel J.A. (1982), "A Test of Perfect Substitutability in the Forward Exchange Market", Southern Economic Journal, pp. 406-16.

Hansen L.P. and Hodrick R.J. (1980), "Forward Exchange Rates as Optimal Predictors of Future Spot Rates: An Econometric Analysis," Journal of Political Economy, Vol. 88, pp. 829-53.

Hodrick L.P. (1987), "The Empirical Evidence on the Efficiency of Forward and Futures Foreign Exchange Markets", in Fundamentals of Pure and Applied Economics, Chur Switzerland: Harwood Academic.

Maynard A and Phillips P.C.B (2001), "Rethinking an Old Empirical Puzzle: Econometric Evidence on the Forward Discount Anomaly", Journal of Applied Econometrics, Vol. 16, pp. 671-708

Sarno L. Valente G. and Leon H. (2006), "Nonlinearity in Deviations from Uncovered Interest Parity: An Explanation of the Forward Bias Puzzle", Review of Finance, Vol. 3, pp. 1-40.

Taylor M.P. (1989), "Expectations, Risk and Uncertainty in the Foreign Exchange Market: Some Results Based on Survey Data", The Manchester School, 57(2), pp. 142-153.

Wang P. and Jones T. (2002), "Testing for Efficiency and Rationality in Foreign Exchange Markets - A Review of the Literature and Research on Foreign Exchange Market Efficiency and Rationality with Comments", Journal of Inernational Money and Finance, Vol. 21, pp. 223-239. 